in vivo $32: 955-960(2018)$

doi:10.21873/invivo.11334

\title{
Increase of Serum Kallikrein-8 Level After Long-term Telbivudine Treatment
}

\author{
HAW-EN WANG ${ }^{1}$, CHIH-LANG LIN ${ }^{2}$, TAI-LONG PAN ${ }^{3}$ and CHAU-TING YEH ${ }^{1}$ \\ ${ }^{1}$ Liver Research Center, Chang Gung Memorial Hospital, Taoyuan, Taiwan, R.O.C.; \\ ${ }^{2}$ Liver Research Unit, Keelung Chang Gung Memorial Hospital, Keelung, Taiwan, R.O.C.; \\ ${ }^{3}$ Research Center for Chinese Herbal Medicine and Research Center for Food and Cosmetic Safety, \\ College of Human Ecology, Chang Gung University of Science and Technology, Taoyuan, Taiwan, R.O.C.
}

\begin{abstract}
Background/Aim: Our previous cDNA microarray study revealed increased cellular $m R N A$ levels of a panel of genes, including kallikrein-8 (KLK8), after long-term telbivudine treatment in chronic hepatitis $B$ patients. The aim of this study was to verify whether serum protein levels of $K L K 8$, a cancer-related enzyme, are indeed increased after telbivudine treatment. Patients and Methods: A total of 83 chronic hepatitis $B$ patients receiving telbivudine for $>2$ years were retrospectively analyzed. Serum KLK8 protein and estimated glomerular filtration rate (eGFR) changes were compared before and after treatment. Results: Both serum $K L K 8$ protein and eGFR increased significantly after longterm telbivudine treatment (paired t-test: KLK8, $p<0.001$; $e G F R, p=0.001)$. No direct correlation was found between KLK8 increase and eGFR change. However, eGFR change was positively associated with post-treatment KLK8 levels following adjustment for body height $(p<0.001)$. Conclusion: Telbivudine treatment resulted in increased levels of serum KLK8 protein. Furthermore, eGFR increase was associated with body height-adjusted, post-treatment KLK8 levels.
\end{abstract}

Hepatitis B is a major global health problem. According to the Global hepatitis report, 2017 of the World Health

This article is freely accessible online.

Correspondence to: Chau-Ting Yeh, MD, PhD, Liver Research Center, Chang Gung Memorial Hospital, 5 Fu-Shin Street, KueiShan District, Taoyuan, Taiwan, R.O.C. Tel: +886 33281200, e-mail: chautingy@gmail.com; Tai-Long Pan, Research Center for Chinese Herbal Medicine and Research Center for Food and Cosmetic Safety, College of Human Ecology, Chang Gung University of Science and Technology, Taoyuan, Taiwan, R.O.C. E-mail:pan@mail.cgu.edu.tw

Key Words: Kallikrein-8, estimated glomerular filtration rate, telbivudine.
Organization report, it chronically infects approximately 240 million people worldwide. Patients with chronic hepatitis B virus (HBV) infection have increased risk of developing hepatic decompensation, liver cirrhosis and hepatocellular carcinoma. Oral antiviral agents are the main choice of chronic hepatitis B infection in the present days. Approved oral antiviral agents include entecavir, tenofovir, telbivudine, lamivudine, and adefovir. These nucleos(t)ide analogues are safe and effective for long-term suppression of hepatitis B virus replication if no drug resistance is developed.

Telbivudine is one of the choices for treatment of chronic hepatitis B (1). Besides its antiviral effect, an increase of estimated glomerular filtration rate (eGFR) has been observed after long-term telbivudine treatment (2). Additionally, increased or decreased mRNA levels in a panel of genes have been found by peripheral blood mononuclear cell-derived cDNA microarray study (3). Of those, decreased serum levels of angiotensinconverting enzyme upon long-term telbivudine treatment have been verified (3). However, of the list of dysregulated genes, up-regulation of kallikrein-8 $(K L K 8)$ gene expression appeared to statistically, be the most significant change.

KLK8 belongs to a group of serine proteases - kallikreins, carrying diverse physiological functions. Many kallikreins are implicated in the development or the regulation of cancers (4, 5). KLK8 is one of the 15 kallikrein subfamily members. Different isoforms of KLK8 mRNA have been reported in the GenBank. The greatest abundance of KLK8 is found in esophagus and skin. Elevated tissue or serum levels of KLK8 have been found in ovarian cancer (6-8), salivary gland tumors (9), endometrial carcinoma (10), and cervical cancer (11). Decreased KLK8 levels have been observed in breast cancer (12). KLK8 serves as a biomarker for poor prognosis in colorectal cancer (13), lung cancer (14), and oral squamous cell carcinoma (15). Conversely, it serves as a biomarker for favorable prognosis in non-small cell lung cancer (16) and ovarian cancer $(17,18)$. Despite these clinical correlations, the actual molecular mechanisms remain unknown. 
Although increased $K L K 8$ mRNA levels after long-term telbivudine treatment were discovered by cDNA microarray analysis, further verification has never been performed. The correlation between the changes in KLK8 levels and eGFR is also unknown. The goal of this study is to verify whether serum KLK8 protein levels indeed increase after telbivudine treatment and if this increase is associated with eGFR changes.

\section{Materials and Methods}

Patients. This study was conducted under the approval of institutional review board, Chang Gung Memorial Hospital, Taiwan. A total of 83 chronic hepatitis B patients receiving long-term telbivudine were analyzed retrospectively. These patients were under regular out-patient follow-ups at Chang Gung Memorial Hospital, Liver Clinic. The duration of telbivudine treatment was $>2$ years for all patients enrolled. The clinical data was collected by reviewing medical records. The KLK8 protein levels and eGFR changes before and after $>2$ years of treatment were assayed and compared

Measurement of KLK8 protein levels. KLK8 protein levels were assayed using human plasma samples derived from patients before or after telbivudine treatment. Plasma samples were retrospectively retrieved from the serum bank, Liver Research Center, Chang Gung Memorial Hospital. Protein concentration was measured using the Bradford Protein Assay Kit (AMRESCO, Inc., Solon, OH, USA). Equal amounts of protein were loaded on gels. Proteins were separated with $10 \%$ SDS-PAGE and transferred to a PVDF membrane. Western blot analysis was performed using KLK8 antibody (Bioss Inc., Woburn, MA, USA) overnight at $4^{\circ} \mathrm{C}$. Blots were washed and incubated with HRP-labeled secondary antibody. Enhanced chemiluminescence was applied for signal detection. The density of Western-blot bands was quantified using GeneTools Image Software. All experiments were technically repeated more than twice. Representative blots are shown in Figure 1A.

\section{Results}

There were totally 83 patients receiving telbivudine treatment for chronic hepatitis B for at least 2 years. The baseline characteristics of these patient are listed in Table I. Of these 83 patients, all had paired KLK8 data before and after treatment, whereas only 53 patients had paired eGFR data. The KLK8 and eGFR levels in each patient were compared before and after treatment. Both serum KLK8 and eGFR levels were increased significantly after $>2$-years of telbivudine therapy (paired $t$-test before and after treatment: KLK8, $p<0.001$; eGFR, $p=0.001$ ) (Figure 1B and C).

The KLK8 protein levels were analyzed by linear regression in relation to age, gender, duration of treatment, aspartate transaminase (AST), alanine transaminase (ALT), $\mathrm{HBV}$ e antigen (HBeAg), antibody against $\mathrm{HBeAg}$ (anti-HBe), initial HBV DNA levels, serum total bilirubin, liver cirrhosis, albumin, body height $(\mathrm{BH})$, body weight $(\mathrm{BW})$ and body mass index (BMI) (Table II). Univariate analysis revealed that the change of KLK8 protein levels was significantly correlated to
Table I. Baseline clinical variables for 83 patients included.

\begin{tabular}{lc}
\hline Variables & Value \\
\hline Age, years, mean \pm SD & $50.5 \pm 12.6$ \\
Gender, male, $\%$ & $60(72.3 \%)$ \\
Duration of treatment, months, Median (range) & $39.1(14.6,100.3)$ \\
AST, U/L, mean \pm SD & $88.6 \pm 89.3$ \\
ALT, U/L, mean \pm SD & $149.5 \pm 173.9$ \\
Bilirubin, mg/dL, mean \pm SD & $1.0 \pm 0.5$ \\
HBeAg, positive, $\%$ & $18(21.7 \%)$ \\
Anti-HBe, positive, $\%$ & $69(83.1 \%)$ \\
HBV-DNA, Meq/ml, Median (range) & $(>640,<0.0002)$ \\
Initial eGFR, mean \pm SD & $91.2 \pm 19.5$ \\
Cirrhosis, Yes, $\%$ & $31(38.6 \%)$ \\
BH, cm, mean \pm SD & $163.7 \pm 8.3$ \\
BW, kg, mean \pm SD & $66.1 \pm 11.6$ \\
BMI, kg/m2, mean \pm SD & $24.5 \pm 3.1$ \\
\hline
\end{tabular}

SD: Standard deviation; AST: aspartate transaminase; ALT: alanine transaminase; eGFR: estimated glomerular filtration rate; $\mathrm{BH}$ : body height; BW: body weight; BMI: body mass index.

$\operatorname{AST}(p=0.012), \operatorname{ALT}(p=0.017), \mathrm{BH}(p=0.030)$, and BW $(p=0.018)$. Multivariate analysis including variables with $p<0.1$ revealed increase of KLK8 protein levels was positively associated with AST $(p=0.004)$ and $\mathrm{BH}(p=0.008)$.

Accordingly, the change of eGFR levels was analyzed by linear regression in relation to age, gender, duration of treatment, AST, ALT, HBeAg, anti-HBe, HBV DNA levels, serum total bilirubin, liver cirrhosis, albumin, initial KLK8 levels, final KLK8 levels, changes of KLK8 levels, BH, BW and BMI (Table III). Univariate analysis revealed that the change of eGFR levels was significantly correlated with gender $(p=0.009)$, $\mathrm{BH}(p=0.002)$, and $\mathrm{BW}(p=0.006)$. Multivariate analysis including variables with $p<0.1$ revealed that the increase of eGFR levels was positively associated with final KLK8 levels $(p=0.017)$ and negatively associated with $\mathrm{BH}(p<0.001)$.

According to these data, no direct correlation between the increase in KLK8 levels and the increase in eGFR levels was found. However, eGFR change was positively associated with the post treatment KLK8 levels following adjustment for BH (Linear regression, $p<0.001$ ) (Figure 2). We further analyzed the relation between initial the KLK8 value (before telbivudine treatment) and $\mathrm{BH}$. It was found that KLK8 initial value was negatively correlated with $\mathrm{BH}$ (Figure 3).

\section{Discussion}

In this study, serum KLK8 levels were found to be significantly increased after prolonged telbivudine treatment. However, despite that both KLK8 and eGFR were increased after treatment, there was no simple linear 

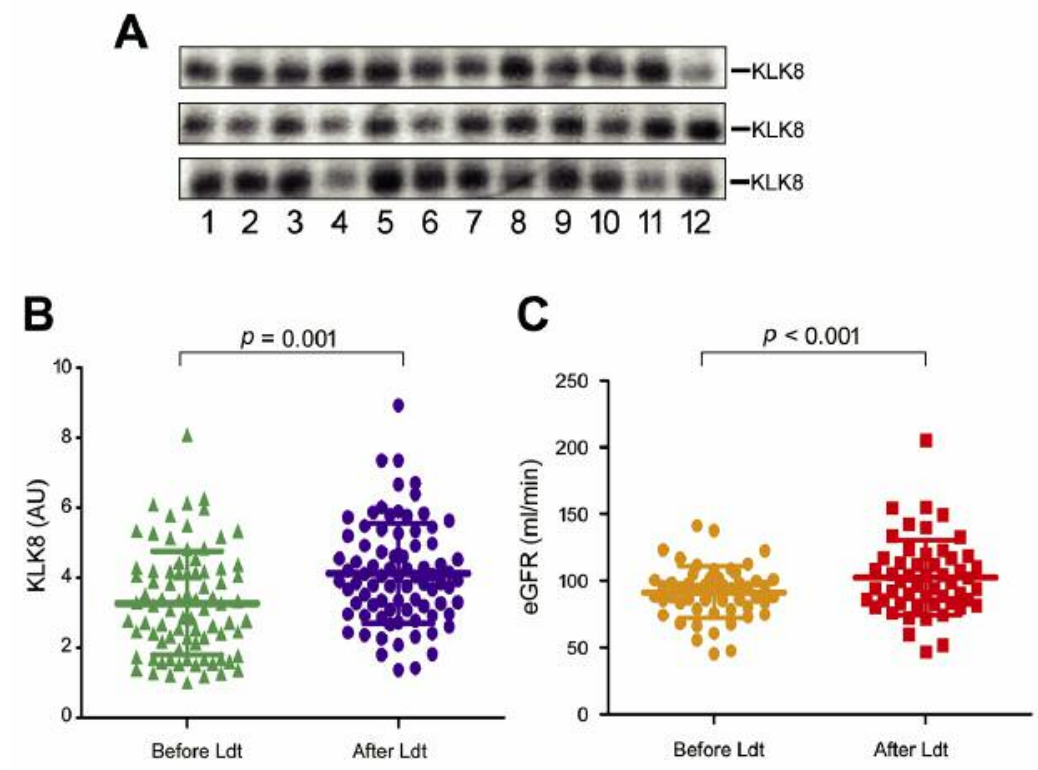

Figure 1. Assessment of serum KLK8 levels and eGFR before and after long-term telbivudine treatment. (A) Representative western blots for quantification of serum KLK8 levels. (B) Comparison of KLK8 levels before and after telbivudine (Ldt) treatment. AU, arbitrary unit, by assigning one sample with lowest KLK8 level as $1 \mathrm{AU}$. (C) Comparison of eGFR before and after telbivudine (Ldt) treatment.

correlation between the two changes. Instead, correlation was found between BH-adjusted, post-treatment KLK8 levels and eGFR changes. The relation between the initial KLK 8 value (before telbivudine treatment) and $\mathrm{BH}$ was further examined. It was found that KLK8 initial value was also correlated with BH (Figure 3). Therefore, KLK8 levels are a BH- dependent factor and adjustment by $\mathrm{BH}$ is needed when correlation with other clinical factors is assessed. The present results suggested that after telbivudine treatment, KLK8 levels had to increase to a certain level (posttreatment KLK8 level, adjusted by $\mathrm{BH}$ ), before significant eGFR increase could occur, while a simple increase of KLK8 levels, if will not reach a sufficient degree, will not associate with eGFR change.

Additionally, in the mostly used equation for eGFR, the MDRD equation, $\mathrm{BH}$ is not an independent predictor for eGFR (19). Therefore, the finding that the eGFR change was positively associated with the post-treatment KLK8 levels, following adjustment for $\mathrm{BH}$, was not biased by the association between eGFR and BH.

KLK8 is a biomarker for prognosis of several cancers (4, $5)$. And, the results of the present study indicate that an increase of KLK8 protein levels occurs after long term telbivudine treatment. Assuming that KLK8 plays a role in pathogenesis of cancers, the telbivudine-induced increase of KLK8 levels can influence the prognosis or associate with progression/regression of the related cancers. Alternatively, telbivudine usage could interfere with the predictive value of

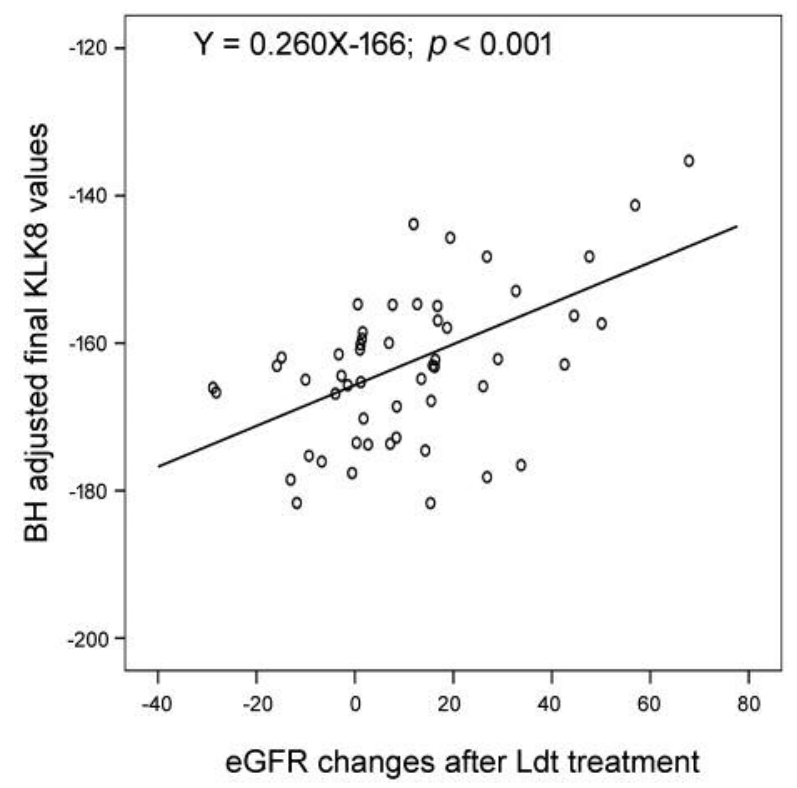

Figure 2. Linear regression analysis between body height $(B H)$ adjusted KLK8 levels (vertical axis) and eGFR changes (horizontal axis) after telbivudine (Ldt) treatment.

KLK8 as a prognostic marker. In the treatment of several cancers, chemotherapy is associated with hepatitis B reactivation (20) and antiviral therapy is recommended in all therapeutic guidelines. The present study suggests that 


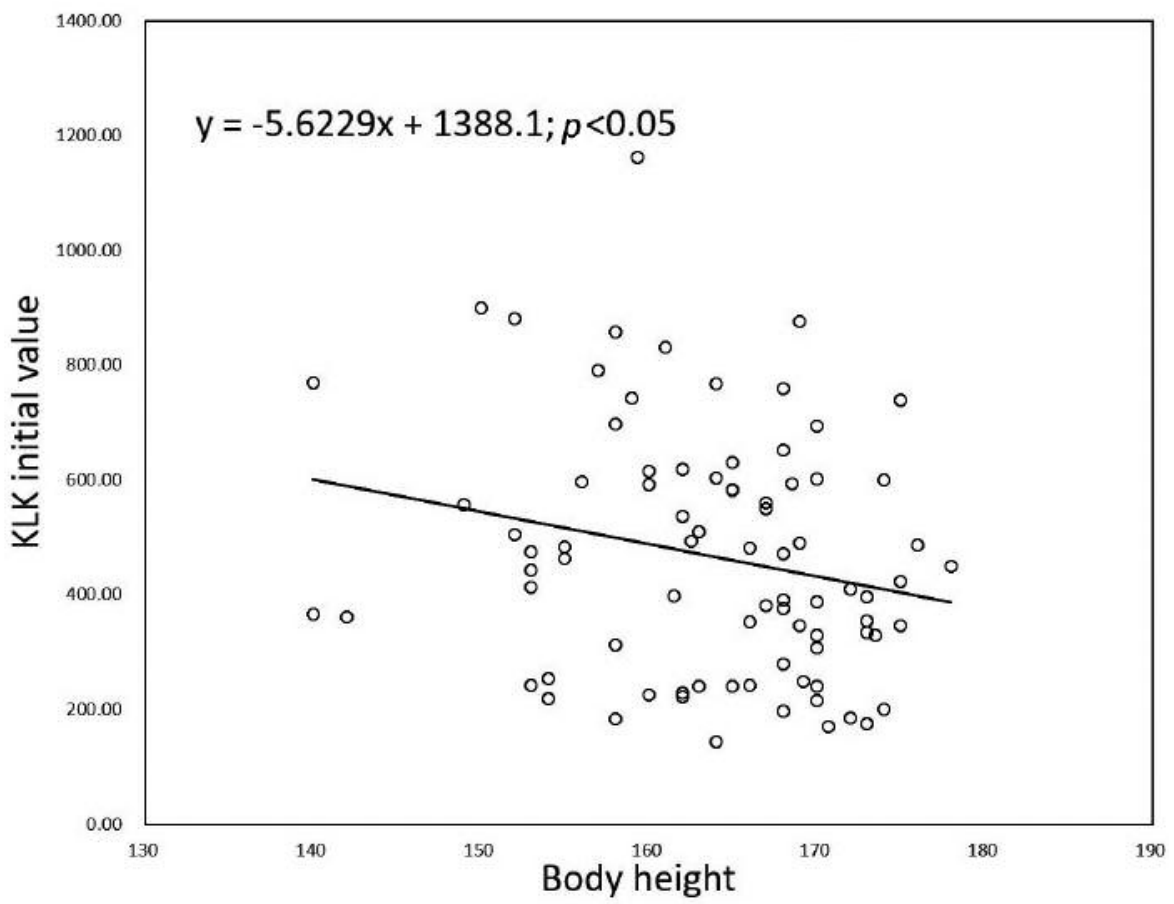

Figure 3. Linear regression analysis between initial KLK8 level (vertical axis) and body height (horizontal axis).

Table II. Linear regression analysis for KLK8 changes after treatment ( $n=83)$.

\begin{tabular}{|c|c|c|c|c|}
\hline Variables & Beta & SE & $95 \% \mathrm{CI}$ & $p$-Value \\
\hline \multicolumn{5}{|l|}{ Univariate analysis } \\
\hline Age & -1.993 & 2.866 & $-7.696,3.709$ & 0.489 \\
\hline Male & 95.576 & 79.806 & $-63.212,254.364$ & 0.235 \\
\hline Duration of treatment & -0.659 & 1.639 & $-3.919,2.601$ & 0.689 \\
\hline AST & 1.007 & 0.390 & $0.230,1.784$ & 0.012 \\
\hline ALT & 0.490 & 0.201 & $0.090,0.890$ & 0.017 \\
\hline $\mathrm{HBeAg}$ & 94.040 & 86.810 & $-78.684,266.764$ & 0.282 \\
\hline Anti-HBe & 90.074 & 95.705 & $-100.348,280.497$ & 0.349 \\
\hline $\mathrm{HBV}-\mathrm{DNA}>2.83 \mathrm{Meq} / \mathrm{ml}$ & 42.677 & 71.916 & $-100.413,185.767$ & 0.555 \\
\hline Bilirubin & 35.440 & 79.993 & $-123.721,194.601$ & 0.659 \\
\hline Cirrhosis & 34.374 & 73.934 & $-112.732,181.479$ & 0.643 \\
\hline Albumin & -205.266 & 176.684 & $-566.626,156.094$ & 0.255 \\
\hline $\mathrm{BH}$ & 9.436 & 4.260 & $0.959,17.913$ & 0.030 \\
\hline BW & 7.331 & 3.033 & $1.296,13.366$ & 0.018 \\
\hline BMI & 18.016 & 11.662 & $-5.192,41.223$ & 0.126 \\
\hline \multicolumn{5}{|c|}{ Multivariate (Stepwise mode; including variables with univariate $p<0.2$ ) } \\
\hline AST & 1.134 & 0.382 & $0.373,1.894$ & 0.004 \\
\hline $\mathrm{BH}$ & 11.262 & 4.112 & $3.077,19.446$ & 0.008 \\
\hline
\end{tabular}

SE: Standard error; AST: aspartate transaminase; ALT: alanine transaminase; eGFR, estimated glomerular filtration rate; BH: body height; BW: body weight; BMI: body mass index.

telbivudine might be a better choice for this purpose in certain type of cancers, such as non-small cell lung cancer
(16) and ovarian cancer $(17,18)$, where the increase of KLK8 has been associated with a better prognosis. 
Table III. Linear regression analysis for eGFR changes after treatment ( $n=53)$.

\begin{tabular}{|c|c|c|c|c|}
\hline Variables & Beta & SE & $95 \% \mathrm{CI}$ & $p$-Value \\
\hline \multicolumn{5}{|l|}{ Univariate analysis } \\
\hline Age & 0.256 & 0.199 & $-0.144,0.655$ & 0.204 \\
\hline Male & -15.275 & 5.621 & $-26.560,-3.989$ & 0.009 \\
\hline Duration of treatment & 0.023 & 0.138 & $-0.255,0.301$ & 0.869 \\
\hline AST & 0.022 & 0.028 & $-0.034,0.077$ & 0.440 \\
\hline ALT & 0.003 & 0.014 & $-0.025,0.032$ & 0.807 \\
\hline $\mathrm{HBeAg}$ & 8.394 & 6.604 & $-4.865,21.652$ & 0.210 \\
\hline Anti-HBe & -1.715 & 7.171 & $-16.112,12.683$ & 0.812 \\
\hline $\mathrm{HBV}-\mathrm{DNA}>2.83 \mathrm{Meq} / \mathrm{ml}$ & 7.967 & 5.553 & $-3.182,19.116$ & 0.157 \\
\hline Bilirubin & -9.588 & 5.555 & $-20.739,1.564$ & 0.090 \\
\hline Cirrhosis & 0.684 & 5.927 & $-11.215,12.584$ & 0.909 \\
\hline Albumin & 2.264 & 10.788 & $-20.315,24.842$ & 0.836 \\
\hline Initial KLK8 & 0.773 & 1.781 & $-2.803,4.350$ & 0.666 \\
\hline Final KLK8 & 3.132 & 1.917 & $-0.717,6.980$ & 0.108 \\
\hline KLK8 changes & 0.005 & 0.008 & $-0.011,0.022$ & 0.509 \\
\hline $\mathrm{BH}$ & -0.989 & 0.306 & $-1.602,-0.375$ & 0.002 \\
\hline BW & -0.727 & 0.252 & $-1.232,-0.222$ & 0.006 \\
\hline BMI & -1.087 & 0.971 & $-3.037,0.863$ & 0.268 \\
\hline \multicolumn{5}{|c|}{ Multivariate (Stepwise mode; including variables with univariate $p<0.2$ ) } \\
\hline $\mathrm{BH}$ & -1.116 & 0.296 & $-1.711,-0.521$ & $<0.001$ \\
\hline Final KLK8 & 4.274 & 1.735 & $0.788,7.759$ & 0.017 \\
\hline
\end{tabular}

SE: Standard error; AST: aspartate transaminase; ALT: alanine transaminase; eGFR: estimated glomerular filtration rate; BH: body height; BW: body weight; BMI: body mass index.

\section{Conclusion}

Long-term ( $>2$ years) telbivudine treatment results in an increase of KLK8 protein levels, besides the increase of eGFR levels. The increase of eGFR was associated with posttreatment KLK8 levels following adjustment for BH. Usage of telbivudine for prevention of hepatitis $\mathrm{B}$ reactivation in cancer patients receiving chemotherapy might also affect the prognosis of cancers through the increase in KLK8 levels.

\section{Acknowledgements}

The Authors appreciate the help from members of the Liver Research Center, Chang Gung Memorial Hospital for critical discussion and assembly of data. This work was supported by Chang Gung Medical Research Program (CORPG3G0971 and CORPG3G0991).

\section{References}

1 Liaw YF, Gane E, Leung N, Zeuzem S, Wang Y, Lai CL, Heathcote EJ, Manns M, Bzowej N and Niu J: 2-year globe trial results: Telbivudine is superior to lamivudine in patients with chronic hepatitis b. Gastroenterology 136(2): 486-495, 2009.

2 Chan H, Chen Y, Gane E, Sarin S, Suh D, Piratvisuth T, Prabhakar B, Hwang S, Choudhuri G and Safadi R: Randomized clinical trial: Efficacy and safety of telbivudine and lamivudine in treatment-naïve patients with hbv-related decompensated cirrhosis. J Viral Hepat 19(10): 732-743, 2012.

3 Liang KH, Chen YC, Hsu CW, Chang ML and Yeh CT: Decrease of serum angiotensin converting enzyme levels upon telbivudine treatment for chronic hepatitis $b$ virus infection and negative correlations between the enzyme levels and estimated glumerular filtration rates. Hepat Mon 14(1): e15074, 2014.

4 Yousef GM and Diamandis EP: The new human tissue kallikrein gene family: Structure, function, and association to disease. Endocrine Rev 22(2): 184-204, 2001.

5 Clements JA, Willemsen NM, Myers SA and Dong Y: The tissue kallikrein family of serine proteases: Functional roles in human disease and potential as clinical biomarkers. Crit Rev Clin Lab Sci 41(3): 265-312, 2004.

6 Kountourakis P, Psyrri A, Scorilas A, Markakis S, Kowalski D, Camp RL, Diamandis EP and Dimopoulos MA: Expression and prognostic significance of kallikrein-related peptidase 8 protein levels in advanced ovarian cancer by using automated quantitative analysis. Thromb Haemost 101(3): 541-546, 2009.

7 Kishi T, Grass L, Soosaipillai A, Scorilas A, Harbeck N, Schmalfeldt B, Dorn J, Mysliwiec M, Schmitt M and Diamandis EP: Human kallikrein 8, a novel biomarker for ovarian carcinoma. Cancer Res 63(11): 2771-2774, 2003.

8 Yousef GM, Polymeris M-E, Yacoub GM, Scorilas A, Soosaipillai A, Popalis C, Fracchioli S, Katsaros D and Diamandis EP: Parallel overexpression of seven kallikrein genes in ovarian cancer. Cancer Res 63(9): 2223-2227, 2003. 
9 Darling MR, Tsai S, Jackson-Boeters L, Daley TD and Diamandis EP: Human kallikrein 8 expression in salivary gland tumors. Head Neck Pathol 2(3): 169-174, 2008.

10 Jin H, Nagai N, Shigemasa K, Gu L, Tanimoto H, Yunokawa M, Ohama K, Kudo Y and O'Brien TJ: Expression of tumorassociated differentially expressed gene-14 (tadg-14/klk8) and its protein $\mathrm{hk} 8$ in uterine endometria and endometrial carcinomas. Tumor Biol 27(5): 274-282, 2006.

11 Bignotti E, Bellone S, Palmieri M, De Las Casas L, Roman JJ, Pecorelli S, Cannon MJ, O'brien T and Santin AD: The novel serine protease tumor-associated differentially expressed gene14 (klk8/neuropsin/ovasin) is highly overexpressed in cervical cancer. AmJ Obstet Gynecol 190(1): 60-66, 2004.

12 Yousef G, Yacoub G, Polymeris M-E, Popalis C, Soosaipillai A and Diamandis E: Kallikrein gene down-regulation in breast cancer. Br J Cancer 90(1): 167, 2004.

13 Liu X, Quan B, Tian Z, Xi H, Jia G, Wang H, Zhang L, Liu R, $\mathrm{Ma} \mathrm{C}$ and Han F: Elevated expression of klk8 predicts poor prognosis in colorectal cancer. Biomed Pharmacother 88: 595602, 2017.

14 Planque C, Choi Y-H, Guyetant S, Heuzé-Vourc'h N, Briollais $\mathrm{L}$ and Courty Y: Alternative splicing variant of kallikrein-related peptidase 8 as an independent predictor of unfavorable prognosis in lung cancer. Clin Chem 56(6): 987-997, 2010.

15 Pettus JR, Johnson JJ, Shi Z, Davis JW, Koblinski J, Ghosh S, Liu Y, Ravosa MJ, Frazier S and Stack MS: Multiple kallikrein (klk 5, 7, 8, and 10) expression in squamous cell carcinoma of the oral cavity. Histol Histopathol 24(2): 197, 2009.
16 Sher Y-P, Chou C-C, Chou R-H, Wu H-M, Chang W-SW, Chen C-H, Yang P-C, Wu C-W, Yu C-L and Peck K: Human kallikrein 8 protease confers a favorable clinical outcome in non-small cell lung cancer by suppressing tumor cell invasiveness. Cancer Res 66(24): 11763-11770, 2006.

17 Borgoño CA, Kishi T, Scorilas A, Harbeck N, Dorn J, Schmalfeldt B, Schmitt M and Diamandis EP: Human kallikrein 8 protein is a favorable prognostic marker in ovarian cancer. Clin Cancer Res 12(5): 1487-1493, 2006.

18 Shigemasa K, Tian X, Gu L, Tanimoto H, Underwood LJ, O'Brien TJ and Ohama K: Human kallikrein 8 (hk8/tadg-14) expression is associated with an early clinical stage and favorable prognosis in ovarian cancer. Oncol Rep 11(6): 11531159,2004

19 Levey AS, Bosch JP, Lewis JB, Greene T, Rogers N and Roth D: A more accurate method to estimate glomerular filtration rate from serum creatinine: A new prediction equation. Ann Intern Med 130(6): 461-470, 1999.

20 Hoofnagle JH, Dusheiko GM, Schafer DF, JONES EA, Micetich $\mathrm{KC}$, Young RC and Costa J: Reactivation of chronic hepatitis $\mathrm{b}$ virus infection by cancer chemotherapy. Ann Intern Med 96(4): 447-449, 1982

Received April 22, 2018

Revised May 8, 2018

Accepted May 9, 2018 